\title{
FINOT PHYSTOOL (Find Out Physics Tools) sebagai Media Pengenalan Alat-Alat Praktikum Fisika Berbasis Aplikasi Game Android
}

\author{
Author(s): Raeka Widi Anggeraeni, Yulika Rahmawati, Monica Merry Febriyana, \& Irnin \\ Agustina Dwi Astuti
}

Editor: Helda Jolanda

Publication details, including author guidelines

URL: https://jlis.idcounselor.com/index.php/jlis/about/submissions

\author{
Article History \\ Received: $1 / 17 / 2021$ \\ Revised: 3/16/2021 \\ Accepted: 4/4/2021
}

How to cite this article (APA)

Anggeraeni, R. W., Rahmawati, Y., Febriyana, M. M., \& Astuti, I. A. D. (2021). FINOT PHYSTOOL (Find Out Physics Tools) sebagai Media Pengenalan Alat-Alat Praktikum Fisika Berbasis Aplikasi Game Android. Journal of Learning and Instructional Studies, 1(1), 1-8. https://doi.org/10.46637/jlis.v1i1.1

The readers can link to article via https://doi.org/10.46637/jlis.v1i1.1

\section{SCROLL DOWN TO READ THIS ARTICLE}

Southeast Asia Mental Health and Counseling Association (as publisher) makes every effort to ensure the accuracy of all the information (the "Content") contained in the publications. However, we make no representations or warranties whatsoever as to the accuracy, completeness, or suitability for any purpose of the Content. Any opinions and views expressed in this publication are the opinions and views of the authors and are not the views of or endorsed by Southeast Asia Mental Health and Counseling Association. The accuracy of the Content should not be relied upon and should be independently verified with primary sources of information. Southeast Asia Mental Health and Counseling Association shall not be liable for any losses, actions, claims, proceedings, demands, costs, expenses, damages, and other liabilities whatsoever or howsoever caused arising directly or indirectly in connection with, in relation to, or arising out of the use of the content.

Journal of Learning and Instructional Studies is published by Southeast Asia Mental Health and Counseling Association comply with the Principles of Transparency and Best Practice in Scholarly Publishing at all stages of the publication process. Journal of Learning and Instructional Studies also may contain links to web sites operated by other parties. These links are provided purely for educational purpose.

\section{(c) (1)}

This work is licensed under a Creative Commons Attribution 4.0 International License.

Copyright by Anggeraeni, et al (2021)

The author(s) whose names are listed in this manuscript declared that they have NO affiliations with or involvement in any organization or entity with any financial interest (such as honoraria; educational grants; participation in speakers' bureaus; membership, employment, consultancies, stock ownership, or other equity interest; and expert testimony or patent-licensing arrangements), or non-financial interest (such as personal or professional relationships, affiliations, knowledge or beliefs) in the subject matter or materials discussed in this manuscript. This statement is signed by all the authors to indicate agreement that the all information in this article is true and correct. 


\title{
FINOT PHYSTOOL (Find Out Physics Tools) sebagai Media Pengenalan Alat-Alat Praktikum Fisika Berbasis Aplikasi Game Android
}

\author{
Raeka Widi Anggeraeni, Yulika Rahmawati, Monica Merry Febriyana, \& Irnin \\ Agustina Dwi Astuti* \\ Universitas Indraprasta PGRI, Jakarta, Indonesia
}

\begin{abstract}
Generally, physics lessons are linked to varied practicums in the laboratory. However, most students did not understand the names of the practicum tools to be used. This also affects practicum activities to be less conducive. Innovation is demanded to promote students recognize useful practicum tools. One of the applications we suggest is FINOT PHYSTOOL (Find Out Physics Tools), an Android game-based physics learning media application that represents the name of the practicum tool and its material concept. This research is a Research \& Development (R\&D) with the ADDIE model. The instruments used were the observation sheet and the validation questionnaire. The results of the analysis show that the average validation value of material experts is $80.50 \%$ and media experts is $84.00 \%$. The total average value of material validation and media validation was $82.25 \%$. This shows that the FINOT PHYSTOOL application developed is feasible to be implemented for students. FINOT PHYSTOOL is easy and flexible to increase student interest in learning while making it easier for students to recognize physics practicum tools.
\end{abstract}

Key Words: Introducing of Practicum Tools; Game Education; Android Platform; Learning Media; Physics Learning.

\begin{abstract}
Abstrak: Umumnya, pelajaran fisika berkaitan dengan berbagai praktikum di laboratorium. Namun, sebagian besar siswa tidak memahami nama-nama alat praktikum yang akan digunakan. Hal ini juga mempengaruhi kegiatan praktikum menjadi kurang kondusif. Diperlukan inovasi untuk membantu peserta didik memahami alat praktikum yang bermanfaat. Salah satu aplikasi yang kami tawarkan adalah FINOT PHYSTOOL (Find Out Physics Tools), aplikasi media pembelajaran fisika berbasis game android yang menampilkan nama alat praktikum dan konsep materialnya. Penelitian ini adalah Research \& Development (R\&D) dengan model ADDIE. Instrumen yang digunakan adalah lembar pengamatan dan kuesioner validasi. Hasil analisis menunjukkan nilai rata-rata validasi ahli materi $80,50 \%$ dan ahli media $84,00 \%$. Nilai rata-rata total dari validasi materi dan validasi media sebesar $82,25 \%$. Ini menunjukkan bahwa aplikasi FINOT PHYSTOOL yang dikembangkan layak diimplementasikan untuk peserta didik. FINOT PHYSTOOL mudah dan fleksibel untuk meningkatkan minat belajar siswa sekaligus memudahkan siswa untuk mengenali alat-alat praktikum fisika.
\end{abstract}

Kata Kunci: Pengenalan Alat Praktikum; Game Edukasi; Platform Android; Media Pembelajaran; Pembelajaran Fisika.

"Corresponding author: Irnin Agustina Dwi Astuti. Universitas Indraprasta PGRI. JI. Nangka Raya No.58 C, RT.5/RW.5, Tj. Bar., Kec. Jagakarsa, Jakarta Selatan, Daerah Khusus Ibukota Jakarta 12530, Indonesia. Email: irnin.agustina@gmail.com 


\section{Pendahuluan}

Kemajuan teknologi informasi dan komunikasi saat ini semakin berkembang dan kemudahan dalam berbagai bidang, salah satunya yaitu dalam bidang pendidikan. Globalisasi mengakibatkan perubahan dunia pendidikan dari yang konvensional ke arah pendidikan yang lebih terbuka (Istiqomah, 2018). Penggunaan metode dan media pembelajaran sangat mempengaruhi proses pembelajaran. Di era sekarang ini, penggunaan smartphone memang sulit untuk dihindari. Penggunaan smartphone di Indonesia belum mengoptimalkan manfaatnya, khususnya di dunia pendidikan. Sebagian besar pelajar dan mahasiswa menggunakan smartphone untuk mengakses jejaring sosial dan bermain game.

Fisika merupakan salah satu mata pelajaran yang memiliki peranan dalam ilmu pengetahuan dan teknologi. Oleh karena itu, perlu adanya media pembelajaran menggunakan teknologi agar proses pembelajaran fisika menjadi lebih menyenangkan, lebih aktif agar peserta didik menjadi termotivasi untuk belajar fisika. Pada umumnya mata pelajaran fisika selalu dilengkapi dengan berbagai macam praktikum yang dilakukan di ruang laboratorium. Kegiatan praktikum fisika penting dilakukan karena untuk meningkatkan keterampilan psikomotorik peserta didik (Kurnianto \& Dwijanant, 2010). Sebelum memulai praktikum, biasanya para peserta didik diwajibkan untuk mengetahui alat dan bahan yang akan digunakan saat praktikum. Namun, tidak sedikit peserta didik yang kurang memahami nama beserta fungsi alat yang akan digunakan di dalam laboratorium.

Berdasarkan observasi dan wawancara dengan beberapa peserta didik di SMA Jakarta diperoleh data bahwa hampir $80 \%$ peserta didik ketika melakukan kegiatan eksperimen tidak membaca panduan praktikum dan tidak mengenal nama-nama alat laboratoriumnya. Padahal alat-alat laboratorium penting untuk diketahui untuk mendukung jalannya proses praktikum. Oleh karena itu, untuk memudahkan pengenalan nama beserta fungsi alat di dalam laboratorium, dibutuhkan sebuah media pembelajaran yang menyediakan materi yang mencakup pengenalan alat laboratorium mulai dari nama alat, fungsi, dan cara penggunaannya secara singkat. Media pembelajaran yang dipilih untuk penelitian ini adalah game edukasi pengenalan alat-alat laboratorium.

Game edukasi adalah salah satu jenis game yang digunakan untuk memberikan pembelajaran kepada penggunanya melalui media permainan yang mudah di pahami (Wati \& Istiqomah, 2019). Game edukasi dikemas untuk merangsang daya pikir termasuk meningkatkan konsentrasi dan memecahkan masalah (Rahman \& Tresnawati, 2016). Pemanfaatan teknologi game edukasi pada proses belajar mengajar merupakan salah satu cara yang tepat, karena game edukasi sebagai media visual memiliki kelebihan dibandingkan dengan media visual lainnya. Game sangat disukai oleh semua umur dari anak-anak hingga orangtua. Anak-anak biasanya lebih menyukai game dibandingkan belajar. Karena game membuat anak menjadi terhibur dan tertantang untuk menyelesaikan sebuah misi. Oleh karena itu, game edukasi ini sangat cocok sebagai media pembelajaran untuk anak-anak. Lebih tertariknya anak-anak kepada smartphone daripada materi belajar yang dijelaskan oleh pendidik tentunya menuntut para pendidik untuk mencari cara lain dalam menarik minat peserta didik untuk belajar (Erfan dkk, 2020). Terlebih lagi saat ini, ketika kegiatan pembelajaran jarak jauh dilakukan dari rumah sehingga banyak peserta didik yang menggunakan smartphone, sebagai suatu media komunikasi dan media belajar. Hal tersebut juga memungkinkan peserta didik untuk bermain game dengan menggunakan smartphone. Pemanfaatan smartphone yang baik adalah jika media ini mampu digunakan dalam pembelajaran.

Berdasarkan pernyataan yang telah dikemukakan di atas, maka dibuatlah sebuah pengembangan teknologi media pembelajaran berbasis aplikasi game android untuk peserta didik jenjang Sekolah Menengah Atas yang berjudul "FINOT PHYSTOOL (Find Out Physics Journal of Learning and Instructional Studies (2021), 1(1), 1-8 https://doi.org/10.46637/jlis.v1i1.1 
Tools) sebagai Pengembangan Teknologi Media Pembelajaran Fisika Berbasis Aplikasi Game Android.

Tujuan yang ingin dicapai dari penelitian ini yaitu untuk membuat rancang bangun FINOT PHYSTOOL (Find Out Physics Tools) sebagai media pengenalan alat-alat praktikum fisika berbasis game android dan untuk mengetahui kelayakan FINOT PHYSTOOL (Find Out Physics Tools) sebagai media pengenalan alat-alat praktikum fisika berbasis aplikasi game android. Adapun manfaat yang dapat diberikan oleh peneliti diantaranya bagi peserta didik yaitu game edukasi ini diharapkan dapat menambah pengetahuan mengenai fisika melalui game edukasi FINOT PHYSTOOL (Find Out Physics Tools) berbasis android yang dapat diakses dimana dan kapan saja dan dapat meningkatkan minat serta daya tarik dalam belajar fisika, sedangkan bagi pendidik/tenaga pengajar yaitu memotivasi pendidik untuk mengembangkan materi pembelajaran dan selalu berinovasi dalam membuat media pembelajaran berbasis teknologi yang menyenangkan bagi peserta didik dan sebagai referensi media pembelajaran yang dapat digunakan di dalam kelas.

\section{MetOde}

Penelitian ini merupakan penelitian Research \& Development (R \& D) dengan model ADDIE yaitu Analysis (Analisis), Design (Desain), Development (Pengembangan), Implementation (Implementasi) dan Evaluation (Evaluasi). Instrumen yang digunakan dalam penelitian ini adalah lembar observasi dan lembar angket validasi. Lembar angket validasi dilakukan untuk menguji kelayakan game edukasi ke pakar yang ahli dibidangnya, yaitu ahli media dan ahli materi.

Analisis instrumen angket digunakan untuk menguji kelayakan produk. Instrumen ini menggunakan skala likert. Kategori jawaban yang disediakan berupa sangat setuju (SST), setuju (ST), tidak setuju (TS), sangat tidak setuju (STS). Jawaban angket diberi bobot 4,3,2,1 untuk pernyataan positif dan 1,2,3,4 untuk pernyataan negatif. Hasil skor individu dinyatakan dengan rata-rata dari semua skor yang diperoleh. Kriteria kelayakan produk terpapar pada Tabel 1.

Tabel 1. Kriteria Kelayakan Media Pembelajaran (Sumber: Astuti dkk, 2017)

\begin{tabular}{ccc}
\hline No & Interval & Kategori \\
\hline 1 & $80 \%-100 \%$ & Valid \\
2 & $60 \%-79,9 \%$ & Cukup Valid \\
3 & $50 \%-59,9 \%$ & Kurang Valid \\
4 & $0-49,9 \%$ & Diganti \\
\hline
\end{tabular}

\section{HASIL DAN DISKUSI}

Hasil dari penelitian pengembangan ini berupa produk game edukasi berbasis android. Game edukasi ini dibuat dan dirancang secara langsung oleh peneliti yang bertujuan untuk mempermudah dan membantu peserta didik dalam mengenali alat maupun benda yang dapat digunakan dalam praktikum yang disesuaikan dengan materi pelajaran. Pengembangan game edukasi ini menggunakan model perancangan ADDIE. Model ADDIE terdiri atas 5 tahapan 
meliputi Analysis (Analisis), Design (Desain), Development (Pengembangan), Implementation (Implementasi) dan Evaluation (Evaluasi). Penelitian pengembangan model ADDIE hanya dilakukan sampai tahap Development (Pengembangan), karena tujuan dari penelitian ini hanya membuat produk game edukasi dan keterbatasan peneliti karena sedang keadaan Pandemi Covid 19 sehingga belum bisa di implementasikan ke peserta didik. Tahap-tahap penelitian pengembangan tersebut diperjelas sebagai berikut:

Tahap Analisis. Tahap analisis dilakukan analisis awal terhadap karakter peserta didik, analisis materi, dan analisis kebutuhan. Analisis karakter peserta didik ditinjau dari kondisi peserta didik saat proses pembelajaran berlangsung. Berdasarkan analisis karakter peserta didik diperoleh beberapa kondisi peserta didik kurang memahami nama alat-alat praktikum saat praktikum berlangsung. Biasanya peserta didik langsung memulai praktikum tanpa membaca petunjuk. Guru juga jarang sekali memperkenalkan nama alat-alat praktikum ke peserta didik. Berdasarkan hasil wawancara dengan beberapa peserta didik diperoleh peserta didik masih banyak yang belum mengerti nama alat-alat laboratorium yang biasa mereka gunakan untuk praktikum. Oleh karena itu, dibutuhkan inovasi sebuah media pembelajaran teknologi berupa game edukasi berbasis android yang digunakan untuk mempermudah peserta didik mengenali nama alat-alat laboratorium.

Tahap Desain. Pada tahap desain, membuat desain atau kerangka dari game edukasi. Di dalam game edukasi berisi gambar-gambar alat praktikum beserta penjelasannya. Alat dan bahan yang digunakan dalam membuat adalah MitApp Inventor, software Photoshop, software CorelDraw, handphone dan laptop.

Tahap Pengembangan. Pada tahap development (pengembangan), game edukasi dibuat sesuai desain dan kerangka isi game edukasi. Setelah game edukasi selesai dibuat, maka langkah selanjutnya adalah memvalidasi game edukasi tersebut ke validator yang ahli di bidangnya.

Tabel 2. Hasil Validasi Game Edukasi Ahli Media

\begin{tabular}{lll}
\hline No & Aspek & Persentase (\%) \\
\hline 1 & Grafika & 82 \\
2 & Pengolahan Program & 84 \\
3 & Penggunaan & 86 \\
& Rata-rata & 84 \\
\hline
\end{tabular}

Setelah divalidasi oleh ahli media, maka diperoleh hasil rata-rata validasi ahli media yaitu sebesar $84 \%$ seperti yang terlihat pada tabel 2 . Pada aspek grafika diperoleh nilai ratarata $82 \%$. Komentar dan saran dari ahli mengenai aspek grafika yaitu tampilan warna background dan ikon atau tombol disesuaikan dengan materi. Pada aspek pengolahan program, diperoleh nilai rata-rata $84 \%$. Game edukasi ini memiliki ketepatan dalam pengolahan program. Akses tombol-tombol yang terdapat di game edukasi ini tidak memiliki delay, sehingga ketika tombolnya di tekan maka akan langsung menjalankan apliaksinya. Aspek penggunaan memiliki rata-rata validasi sebesar 86\%. Game eduakasi ini mudah digunakan dan mudah dibawa juga. Dalam menjalankan aplikasi game edukasi ini pengguna tidak memerlukan akses internet. Hal ini berarti penggunaan aplikasi game edukasi bisa diakses secara offline. 
Tabel 3. Hasil Validasi Game Edukasi Ahli Materi

\begin{tabular}{ccc}
\hline No & Aspek & Persentase (\%) \\
\hline 1 & Kesesuain materi & 81 \\
2 & Kesesuain praktikum & 81 \\
3 & Aspek penilaiain & 79 \\
4 & Kebahasaan & 82 \\
& Rata-rata & 80,5 \\
\hline
\end{tabular}

Hasil validasi ahli materi diperoleh rata-rata 80,5\% seperti yang terlihat pada Tabel 3 . Pada aspek kesesuaian materi diperoleh nilai rata-rata $81 \%$. Materi yang ditampilkan di game edukasi sudah disesuaikan dengan materi fisika. Pada aspek kesesuaian praktikum diperoleh nilai rata-rata $81 \%$. Game edukasi ini sudah disesuaikan dengan praktikum fisika. Pengenalan alat-alat praktikum yang ada di game edukasi ini dibagi dalam beberapa kajian bidang fisika. Pada aspek penilaian diperoleh nilai rata-rata 79\%. Game edukasi ini menampilkan tingkat kesulitan yang berbeda-beda. Hal ini untuk mengetahui pemahaman peserta didik dalam pengenalan alat-alat praktikum. Pada aspek bahasa diperoleh nilai rata-rata sebesar $82 \%$. Bahasa yang terdapat dalam game edukasi ini jelas dan mudah dipahami. Saran dan masukan yang sudah diperbaiki diantaranya yaitu menentukan tingkat kesulitan game lebih spesifik dan alat-alat praktikum yang ditampilkan dalam game edukasi ditambah lagi.

Berdasarkan hasil validasi dari kedua ahli materi dan ahli media maka diperoleh nilai rata-rata validator sebesar $82,25 \%$. Hal tersebut menunjukkan bahwa aplikasi FINOT PHYSTOOL yang dikembangkan valid, yang berarti layak untuk diujicobakan ke peserta didik. Setelah produk media diperbaiki sesuai saran dan masukan para validator, maka diperoleh game edukasi berbasis android yang dapat diimplementasikan ke peserta didik.
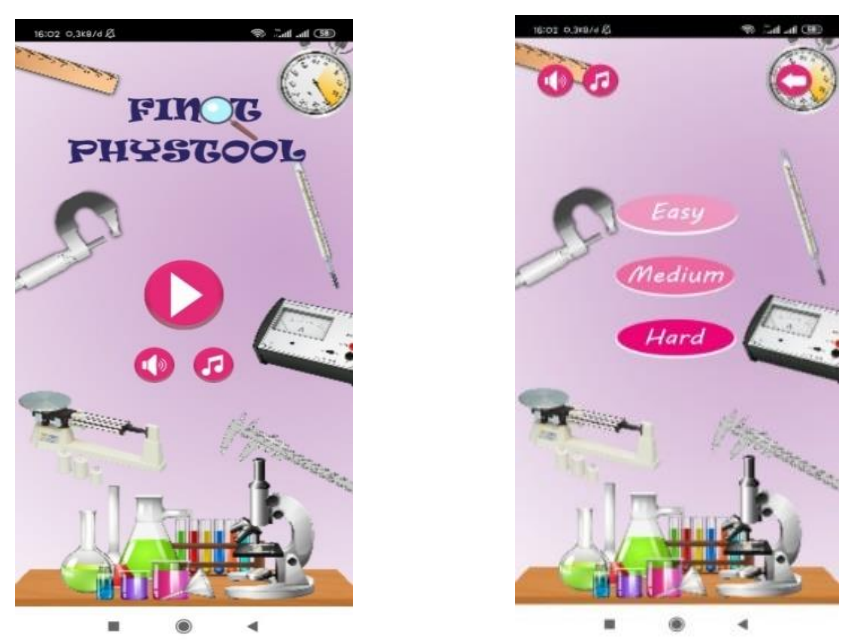

Gambar 1 Tampilan Awal Game Finot Phystool Berbasis Android

Pada Gambar 1 merupakan tampilan awal game FINOT PHYSTOOL berbasis android. Untuk tampilan awal terdapat tombol play yang akan masuk ke tampilan berikutnya atau slide berikutnya yaitu menu tingkat kesulitan game. Di menu tingkat kesulitan game ini terdapat 
tiga kategori yaitu easy, medium, dan hard. Peserta didik bisa memainkan game ini dari tingkat yang mudah terlebih dahulu yaitu tingkat easy. Ketika sudah memilih tingkat kesulitan game, maka selanjutnya akan muncul tampilan menu atau materi dari setiap tingkatan, ditunjukkan pada Gambar 3.
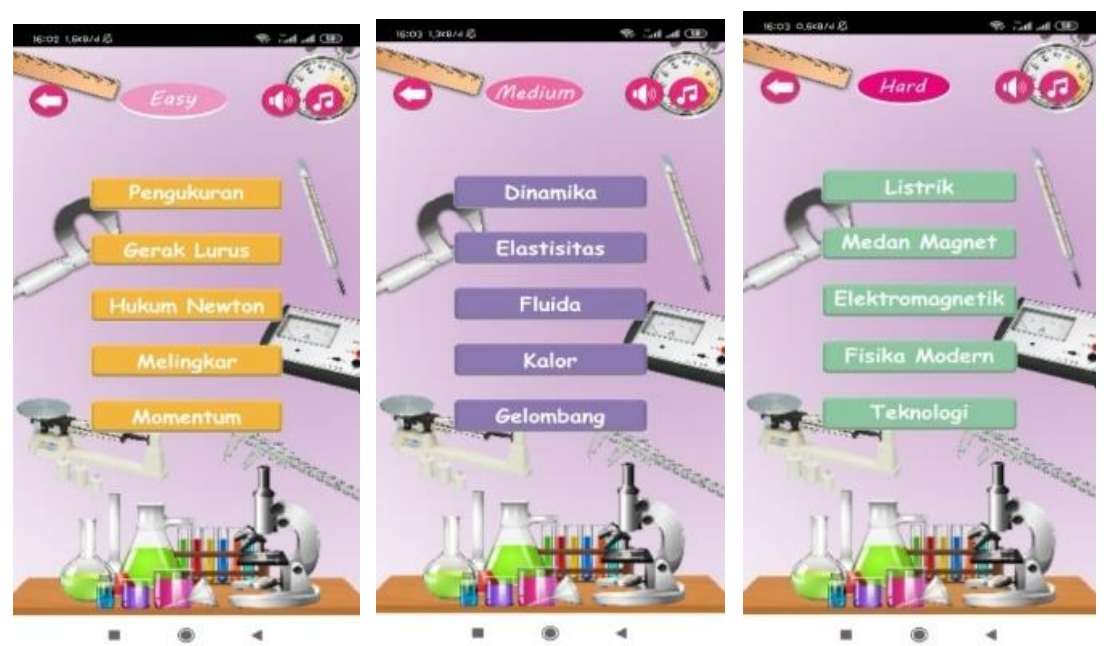

Gambar 2 Tampilan Materi Tingkat Kesulitan Game Finot Phystool Berbasis Android

Tampilan di menu tingkat easy terdapat menu materi-materi dengan kategori mudah seperti pengukuran, gerak lurus, gerak melingkat, hukum newton, dan momentum. Materimateri tersebut tergolong masih mudah karena masih dasar. Sedangkan untuk game dengan tingkat medium berisi materi dinamika, elastisitas, fluida, kalor, dan gelombang. Pada tingkat hard terdapat materi listrik, medan magnet, elektromagnetik, fisika modern, dan teknologi. Materi-materi tersebut tergolong kompleks.
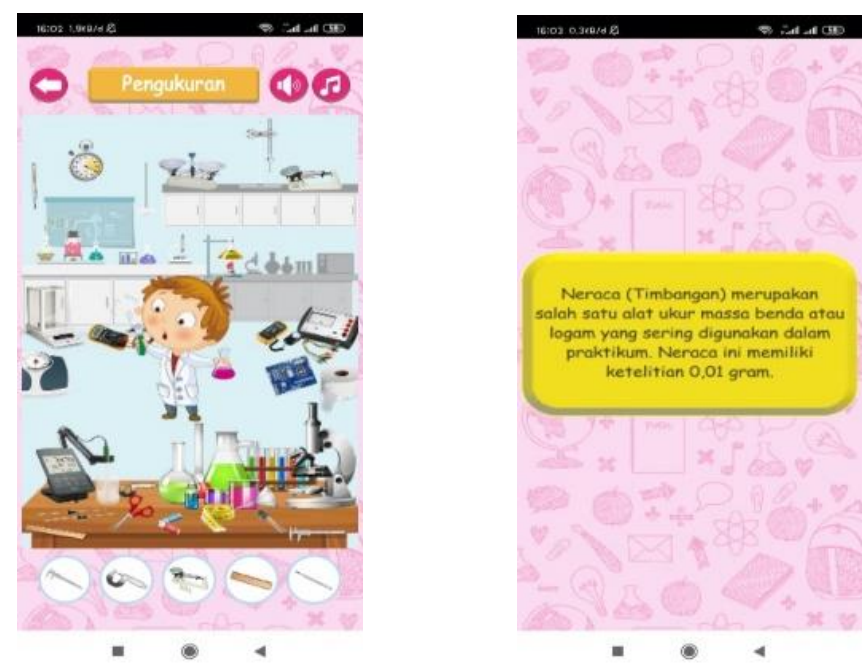

Gambar 3 Tampilan Misi Pada Game Finot Phystool Berbasis Android

Langkah-langkah dalam menggunakan gameandroid FINOT PHYSTOOL yaitu pertama, buka aplikasi FINOT PHYSTOOL yang telah di-instal pada android. Kedua, terdapat tampilan awal, klik tombol play untuk mulai memainkan game. Ketiga, terdapat tampilan berupa tingkat kesulitan dalam game tersebut seperti easy, medium dan hard, Journal of Learning and Instructional Studies (2021), 1(1), 1-8 https://doi.org/10.46637/jlis.v1i1.1 
kemudian pilih dan klik tingkat kesulitan yang diinginkan. Keempat, terdapat tampilan daftar beberapa materi yang akan dimainkan, kemudian pilih dan klik materi. Kelima, game FINOT PHYSTOOL dapat dimainkan.

Cara memainkan game FINOT PHYSTOOL ini adalah dengan mencari beberapa benda yang sudah terdapat pada layar. Ketika telah menemukan benda yang dicari, maka akan muncul suatu penjelasan mengenai benda tersebut. Setelah peserta didik membaca penjelasan tersebut, kemudian mengklik tombol kembali untuk melanjutkan permainan hingga selesai. Tiap benda yang dicari selalu ada penjelasan tentang penggunaan benda dan fungsinya.

Game edukasi merupakan salah satu inovasi media pembelajaran dengan memanfaatkan teknologi smartphone. Dengan menggunakan aplikasi FINOT PHYSTOOL maka peserta didik bisa belajar sambil bermain pengenalan alat-alat laboratorium. Peserta didik tidak perlu belajar tatap muka mengenai pengenalan alat-alat laboratorium karena situasi saat ini yang tidak memungkinkan untuk berlangsung tatap muka. Oleh karena itu, aplikasi FINOT PHYSTOOL sangat mendukung pembelajaran online di new normal saat ini. Tampilan yang menarik dan interaktif ini tentunya menjadi solusi pembelajaran fisika agar diminati oleh peserta didik. Sesuai dengan pendapat Fithri \& Setiawan (2017) game edukasi salah satu media pembelajaran yang dapat meningkatkan motivasi belajar, karena tampilannya yang interaktif dan mengubah pola belajar agar tidak jenuh.Bermain game dapat meningkatkan kemampuan kognitif anak, termasuk spatial navigation, persepsi, daya ingat, sampai pemikiran kritis (Pratama \& Haryanto, 2017). Dengan menggunakan game edukasi berbasis android dalam pembelajaran fisika akan menampilkan konsep-konsep yang abstrak yang bias dijelaskan dengan mudah (Walelang dkk, 2015).

Media pembelajaran berbasis android mendukung pembelajaran online learning. Seperti pendapat Dasmo dkk (2020), media pembelajaran berbasis android efektif dan efisien jika digunakan dalam pembelajaran online untuk mengatasi keterbatasan waktu ketika pembelajaran di kelas. Media pembelajaran menjadikan salah satu senjata dan inovasi yang harus dikuasai guru untuk menunjang proses pembelajaran agar pembelajaran yang disampaikan dapat diterima oleh peserta didik dengan baik. Game edukasi banyak yang sudah membuat dan memanfaatkannya untuk digunakan dalam proses pembelajaran di kelas, namun masih terbatas ke konsep teori, belum ada yang membuat untuk kegiatan praktikum ataupun pengenalan alat-alat praktikum. Kelebihan dari aplikasi FINOT PHYSTOOL adalah peserta bisa belajar secara mandiri dengan aplikasi tersebut untuk pengenalan alat-alat praktikum fisika tanpa kita harus datang langsung ke laboratorium fisika.Dan aplikasi ini dilengkapi dengan penjelasan mengenai alat tersebut, sehingga menambah pemahaman materi dan konsep fisika juga.

\section{SIMPULAN}

Game edukasi ini dibuat dan dirancang secara langsung dengan tujuan untuk mempermudah dan membantu peserta didik dalam mengenali alat maupun benda yang dapat digunakan dalam praktikum yang disesuaikan dengan bab materi pelajaran. Berdasarkan hasil dan pembahasan, maka dapat disimpulkan bahwa aplikasi FINOT PHYSTOOL diperoleh nilai rata-rata persentase dari tiap validasi yaitu validator ahli materi $80,50 \%$ dan validator ahli media $84,00 \%$. Jika dirata-ratakan dari kedua nilai rata-rata validator hasilnya sebesar $82,25 \%$. Hal tersebut menunjukkan bahwa aplikasi FINOT PHYSTOOL yang dikembangkan sudah sangat layak untuk diujicobakan ke peserta didik. Aplikasi FINOT PHYSTOOL sangat mudah digunakan dan fleksibel tanpa batasan ruang dan waktu sehingga diharapkan dapat meningkatkan minat belajar peserta didik. 


\section{References}

Arifin, T., Rosidin, U., \& Wahyudi, I. (2015). Pengembangan Media Sains Berbasis Game Edukasi pada Materi Tata Surya. Jurnal Pembelajaran Fisika, 3(2).

Astuti, I. A. D., Sumarni, R. A., \& Saraswati, D. L. (2017). Pengembangan Media Pembelajaran Fisika Mobile Learning Berbasis Android. Jurnal Penelitian \& Pengembangan Pendidikan Fisika, $3(1), 57-62$.

Astuti, I. A. D., \& Bhakti, Y. B. (2018). Interactive Learning Multimedia Based Microsoft Excel On The Temperature And Heat. Unnes Science Education Journal, 7(1).

Dasmo, D., Astuti, I. A. D., \& Nurullaeli, N. (2017). Pengembangan Pocket Mobile Learning Berbasis Android. Jurnal Riset dan Kajian Pendidikan Fisika, 4(2), 71-77.

Erfan, M., Widodo, A., Umar, U., Radiusman, R., \& Ratu, T. (2020). Pengembangan Game Edukasi "Kata Fisika" Berbasis Android Untuk Anak Sekolah Dasar Pada Materi Konsep Gaya. Lectura: Jurnal Pendidikan, 11(1).

Fatimah, S., \& Mufti, Y. (2014). Pengembangan Media Pembelajaran IPA-Fisika Smartphone Berbasis Android Sebagai Penguat Karakter Sains Peserta Didik. Jurnal Kaunia, 10(1), 59-64.

Fithri, D. L., \& Setiawan, D. A. (2017). Analisa Dan Perancangan Game Edukasi Sebagai Motivasi Belajar Untuk Anak Usia Dini. Simetris: Jurnal Teknik Mesin, Elektro dan Ilmu Komputer, $8(1), 225-230$.

Kurnianto, P., \& Dwijanant, P. (2010). Pengembangan Kemampuan Menyimpulkan Dan Mengkomunikasikan Konsep Fisika Melalui Kegiatan Praktikum Fisika Sederhana. Jurnal Pendidikan Fisika Indonesia, 6(1).

Pratama, U. N, \& Haryanto. (2017). Pengembangan Game Edukasi Berbasis Android Tentang Domain Teknologi Pendidikan. Jurnal Inovasi Teknologi Pendidikan, 4(2), 2460-7177.

Purmadi, A., \& Surjono, H. D. (2016). Pengembangan Bahan Ajar Berbasis Web Berdasarkan Gaya Belajar Peserta Didik Untuk Mata Pelajaran Fisika. Jurnal Inovasi Teknologi Pendidikan, 3(2), 151-165.

Putriana, E. P. (2019). Pengembangan Media Game Edukasi Berbasis Android Dengan Model Problem Based Learning Pada Muatan Pelajaran IPA Kelas IVA SD Negeri Wonosari 03 (Doctoral dissertation, UNNES).

Rasyid, A., Arif, A., \& Kurnia, M. (2019). Pengembangan Media Pembelajaran Berbantuan Game Android Untuk Meningkatkan Kemampuan Berpikir Kritis Siswa. In Prosiding Seminar Nasional Pascasarjana (PROSNAMPAS), vol. 2, no. 1, pp. 16-22.

Rahman, R. A., \& Tresnawati, D. (2016). Pengembangan Game Edukasi Pengenalan Nama Hewan Dan Habitatnya Dalam 3 Bahasa Sebagai Media Pembelajaran Berbasis Multimedia. Jurnal Algoritma, 13(1), 184-190.

Rozi, F., \& Kristari, A. (2020). Pengembangan Media Pembelajaran Game Edukasi Berbasis Android Pada Mata Pelajaran Fisika Untuk Siswa Kelas Xi Di Sman 1 Tulungagung. JIPI (Jurnal Ilmiah Penelitian dan Pembelajaran Informatika), 5(1), 35-44.

Walelang, A. V., Liliana, L., \& Budhi, G. S. (2015). Game Pembelajaran Fisika Dengan Game Bertipe Adventure Game. Jurnal Infra, 3(2), 346-352.

Wati, W., \& Istiqomah, H. (2019). Game Edukasi Fisika Berbasis Smartphone Android Sebagai Media Pembelajaran Fisika. Indonesian Journal of Science and Mathematics Education, 2(2), 162-167.

Wijayanto, E. (2017). Pengaruh Penggunaan Media Game Edukasi Terhadap Hasil Belajar IPA Peserta Didik Kelas IV SDN Kajartengguli Prambon Sidoarjo. Jurnal Penelitian Pendidikan Guru Sekolah Dasar, 5(3).

Journal of Learning and Instructional Studies (2021), 1(1), 1-8 